\title{
Skills and Professional Training Requirements for Librarians of the Mtn-Net Library of Kashim Ibrahim Library, Ahmadu Bello University Zaria
}

\author{
Esew, Michael ${ }^{1}$, Aisha Jimada ${ }^{2}$, Suleiman Hussaini ${ }^{3}$, Habiba Alkasim ${ }^{4}$, Bilkisu \\ Abdullahi Mahadi ${ }^{5}$ \\ 1,2,3,4,5 (Kashim Ibrahim Library Ahmadu Bello University Zaria)
}

\begin{abstract}
The study on skills and professional training requirements for Librarians of the MTN-Net Library of the Kashim Ibrahim Library of the Ahmadu Bello University (A.B.U.), Zaria is to enable the understanding of the skills and professional training needed for the librarians to meet the needs of patrons in the emergence of electronic resources. The study utilized survey research methods and data were collected with the aid of questionnaires. Staff of MTN-Net Library and the Kashim Ibrahim Library of Ahmadu Bello University (A.B.U.), Zaria were interviewed to confirm the response on the questionnaire. The result is analysed with the aid of descriptive statistics and presented in percentages and tabular forms. The research indicated insufficient knowledge and skills for the academics librarians as well as lack of web technology and automation trainings. Recommendations were made regarding library automation and web technology training to both the senior and junior staff and the librarians to enable them effectively and efficiently work in an electronic environment.
\end{abstract}

\section{Introduction}

The on-line environment particularly the World Wide Web has an unstructured environment and the advancement in technology has made it possible for anyone with the necessary technology and skills to post anything on the internet without independent review and evaluation resulting to unreliable information on the internet (Gbaje, 2007). The emergence of the digital age has seen the libraries automate their core operations like circulation, serial and cataloguing. Libraries have also created website which facilitate access to their local resources outside the library. Patrons can now search on-line databases and access the library website remotely, independent of time and distance, thereby transforming the use of library materials and the way library provides it services. New techniques for identifying, locating, accessing, transferring, analyzing, manipulating, comparing, and revising texts, images and data has also been developed. This has a direct impact on the role of academic librarians in meeting the information needs of its patrons. Advancement in technology has made it possible for anyone with the necessary technology and skills to post anything on the Internet without independent review and evaluation. Academic libraries in particular have witness a surge in the number of computers and internet accessible work stations for patrons and library staff. The implication is that like their counterparts in developed countries Nigerian academic librarians need additional knowledge and skills for work within the digital information world. The depth and level required for a new professional is another important aspect of skill. Obviously, it should be as close to the depth and level of his knowledge in the profession. In other words, there should not be wide gap between theoretical knowledge and resultant aspirations, about e-world and practical skills required to operationalize the functions and services in the e- world.

\section{Purpose of the study}

1. To identify the types of information resources requested by patrons make in the MTN- Net library.

2. To identify the types of trainings that will enhance effective service delivery to patrons by the professional and other staff of the MTN-Net library

3. To proffer solutions to the identified challenges detrimental to the objectives of the MTN-Net library and fully exploitation, and sustenance of the emerged electronic resources.

\section{Ahmadu Bello University Libraries}

The Ahmadu Bello University, Nigeria was established in 1962, it comprises twelve faculties, postgraduate school and 81 academic departments, five institutes, six specialized centres and a Division of Agricultural College. The total student enrolment in the university's degree and sub-degree programs is about 35,000 drawn from every state of the federation, Africa and the rest of the world. There are about 1,400 academic and research staff and 5,000 support staff serving the university. The university library system 
comprises the Kashim Ibrahim Library (the main library) MTN net library and eleven other satellite libraries located in different places in the university. The library has a total holding of about 1.2 million volumes of books and 66,000 periodical titles. The university library has always been at the centre of research and scholarship playing a major role in acquiring, processing and inquiries. Today, online database and internet searches are a common feature among staff and students of the university.

The library has staff strength of 42 professionals and 109 para-professionals, 22 senior and 102 junior non-professional staff serving in the library complex. The library management is striving to upgrade the IT skills of the staff and the professional librarian of the MTN net library to enable them cope with the challenges of the information age.

The affordable cost of computers for the past five years has enabled many academic libraries to acquire computers for improving internal workflow and accessing electronic resources within and outside the library. International donors that comprised of MacArthur foundation, the Carnegie Corporation, and MTN have also played major roles in providing computer and internet facilities in Kashim Ibrahim and satellite libraries. Today, the university system can boast of having about 200 computers, with almost one-fourth of it being used by the staff of the library for various day-to-day activities in the library while the remaining can be accessed and used by the patrons. The availability of these computers has enabled the library to establish new sections and units, some of which include the resource centre with about 20 workstations where patrons search CD-Rom collections and the library on-line catalogue, a training workshop for staff and patrons are organized.

The MTN Foundation was incorporated in July 2004 following the resolution by the board of directors of MTN Nigeria to invest $1 \%$ of its profit after tax propagating its corporate social responsibility philosophy. Sequel to its corporation, the foundation held consultations with a wide stakeholder base in September, 2004 to determine the needs of the people. The results have led to a clearly defined strategic perspective on areas of need. The key areas are education, health and economic empowerment. The MTN vision is to improve the quality of life in communities all over Nigeria and committed to partnering with private, public and civil society organization to execute sustainable projects in three focus areas. The foundation in collaboration with tertiary institutions addresses the challenge to access to educational resources, opportunities and information. The diversification has also provides for and facilitate the economic empowerment of Nigerian citizens by alleviating health challenges currently facing the country.

The thrust of the Foundation on educational development is fundamental as it ensures the effective application of information technology in education. According to Amina Oyagbola, Executive Director of the MTN Foundation:

"We believe that access to both education and technology are vital to success in today's world. The digital divide, is a euphemism for knowledge between those who have access to the capacity building tools of the $21^{\mathrm{s}_{1}}$ century and those who do not".

The MTN Foundation is committed to investing in education such that the various levels -primary, secondary, and tertiary are positively affected. The objectives are: to empower through the provision of information and technology resources.

- To enable skills acquisition, transfer and development

- To raise national literacy level

- To provide educational resources for effective learning

\section{MTN Foundation Universities Connect}

In the present digital world, the role of Nigerian libraries has changed dramatically from the provision of physical books, to a network of information resources across the globe. The MTN Foundation Universities Connect Project provides a link to the world's largest collection of digital resources from over 5,500 libraries and 300 publishers to assist university students and lecturers in their research activities. The information resources are also beneficial to the government, the media, industries, etc. The project which is managed by Net Library Nigeria, was first launched in the University of Lagos. The second is the Ahmadu Bello University, Zaria; and the third University of Nigeria Nsukka. The project is planned to be spread along selected universities in the 6 geopolitical zones of the nation.

\section{Requisite Skills and Training Professionals for Efficient Service Delivery in ABU MTN-Net Library}

The MTN-Universities connect staff training for the acquisition of requisite skills and competences workshop was facilitated by Sabinet online (South Africa) and sponsored by Net Library. Twelve participants of the training workshop were selected by the ABU library management who came from different divisions. The workshop delve on the following areas: Online Reference system, Request system (Interlibrary Loan), Cataloguing, Ebscohost databases Worldcat cataloguing. The training started with introduction and installation instructions of appropriate soft and hardware which includes SANB, UCTD/NAV Tech and Book Data THE INTER LIBRARY LOAN (Request System). This software programme is a complete-resource 
sharing system that integrate OPAC data, local policies, standard base communication and a platform that provide interaction between the borrower and the lending libraries.

The Worldcat Cataloguing: This is the world's largest bibliographic databases that merge the catalogues of thousands of OCLC member libraries built and maintained collectively by librarians.

Internet Training and Development of Skills by the Nigerian Library Association with Funding by the Carnegie Corporation's

The sponsorship of six head of libraries in Nigeria to a workshop in Johannesburg in July 2004 ignited the fuse that launched formal internet training in Ahmadu Bello University library complex. The university librarians invited to Johannesburg include that of University of Jos, University of Ibadan, Obafemi Awolowo University, University of Port-Harcourt, Ahmadu Bello University, Zaria and Bayero University Kano, others invited not from Nigeria were from South, East and West Africa to share experiences on the best practices in the use of ICTs in libraries. The title of the workshop is "ICTs and the library; Experiences, opportunity and challenges for libraries in Africa" spelt out the content, in a nutshell, of what several of the libraries experienced.

The Librarian of Kashim Ibrahim Library, on returning intensified efforts by immediately putting in place a befitting ICT infrastructure, thanks to funding from the MacAurthur Foundation, which equipped a large room for formal training in the use of several databases most of which were donated (Bozimo, 2003).

The internet training targeted at all academic staff and postgraduate students on the use of free and a few proprietary electronic databases donated or bought. The sources consist of hundreds of journal titles providing full text articles and sometimes abstracts only. The library, thanks to the Rockefeller Foundation, had hundreds of CD-ROMS in Agriculture literature (TEEAL) which were also heavily used by several other researchers.

The training was carried out according to faculties with emphasis on the Medicine, Agriculture and the Pure sciences, because of the large number of databases in these disciplines (e.g. Hinari and AGORA). Recently, the library's access to the literature of the social sciences and the humanities has been enhanced, indeed for all libraries in Africa, by the MacArthurs foundation donation to JSTOR. As of the middle of 2006, the library had trained close to 500 academic staff and postgraduate students. Bozimo (2003) observed that the following challenges were faced on the internet training. Most people who came for training were uneven in their mastery of the new technologies. This posed a problem in the training sessions, some got easily bored and the need to teach computer appreciation instead of information literacy became imperative. This affected some of the databases released for trial. The frustration mounted by very poor funding of the library deterred the university library from promptly subscribing affecting schedules for training, sensitization and access by the university community.

\section{The Training of the Nigeria Librarian for the 21st Century}

According to Zhou (2005), training the librarian for the $21^{\text {st }}$ century should focus on developing and the acquisition of skills to be able to select, acquire, preserve, organize and manage collection; establish friendly user interface over network; Set up relative standards and policies for a library; design, maintain, transmit, addvalue to information products; protect the intellectual property of authors and to insure information security. $\mathrm{He}$ also advocated for been able to analyze and process different kinds of information resources; activating and finding potential value hidden in any information; providing added-value information products at right time and right place; Finding the right users for information and provide personalized and tailored services.

\section{Methodology}

In order to carry out this study, the survey research was adopted. This method was adopted due to the large size of the population intended for the study. The method involves gathering of data about a target. Population from a sample and generalizing the funding obtained to the population since every respondent cannot be reached easily. As maintained by Nwana (2005) survey research method seems to be the best that is suitable for studies where the population is large over a wide area. Survey research also allows for fast data collection.

\section{Findings}

The Table above listed the types of services provided to the patron of MTN-Net library and the Kashim Ibrahim Library of the Ahmadu Bello University (A.B.U.), Zaria.

\begin{tabular}{|l|l|l|}
\hline Types of Services & Frequency & Percentage \\
\hline Reference Services & 2 & 6.1 \\
\hline Database Search & 3 & 9.1 \\
\hline CDROM database Search & 6 & 18.2 \\
\hline Interlibrary Loan & 1 & 3.0 \\
\hline Document Delivery & 2 & 6.1 \\
\hline Specific website & 3 & 9.1 \\
\hline On-line & 7 & 21.2 \\
\hline
\end{tabular}




\begin{tabular}{|l|l|l|}
\hline Cataloquing & & \\
\hline None of the & 9 & 27.2 \\
\hline Total & $\mathbf{3 3}$ & $\mathbf{1 0 0} \%$ \\
\hline
\end{tabular}

The table above shows the response of the respondents on the types of services provided to the patrons of the MTN-Net library and the Kashim Ibrahim library of Ahmadu Bello University Zaria. This shows that $2(6.1 \%)$ were provided on-line reference services, $3(9.1 \%)$ were provided with on-line database, $6(18.2 \%)$ were provided with CD-Rom database search,. 1(3.0\%) were provided with on-line inter-library loan and 7(21.1\%) were provided with online cataloguing. This indicates that online cataloguing with $7(21.2 \%)$ respondents is the highest service, provided to the patrons of MTN-Net library and the Kashim Ibrahim library of (A.B.U.) Zaria. This is because most of the staff are familiar with how to use the computer in their offices to carryout their duties especially in the Cataloguing Division in the Kashim Ibrahim Library of Ahmadu Bello University where books are charged and discharged using the computer systems. This finding has to do the various training the staff receives. For example recently the library management have sent some staff for some automation training in Kogi, Ilorin, and Abuja. The least in the table is the on-line interlibrary loan with 1(3.0\%) respondents, the reason is because majority of the libraries are not on-line so they find it difficult to meet the needs of the patrons and that is why MTN Foundation is making effort to train their staff on library automation and to establish the Net libraries in colleges and tertiary institutions which Ahmadu Bello University is a beneficiary of this programme. This is to help meet the needs of the patrons in the digital age.

\section{Proficiency of web technology by the staff}

\begin{tabular}{|l|l|l|}
\hline Web technology & Frequency & Percentage \\
\hline Specific website & 1 & $\mathbf{2 . 9}$ \\
\hline Library website & 5 & 14.3 \\
\hline E-mail & 9 & 25.7 \\
\hline Instant message & - & - \\
\hline Electronic book & 5 & 14.3 \\
\hline $\begin{array}{l}\text { Information } \\
\text { subscription }\end{array}$ & 1 & 2.9 \\
\hline On-line news & 3 & 8.6 \\
\hline On-line books & 2 & 5.7 \\
\hline On-line database & 2 & 5.7 \\
\hline Blogs & 4 & 11.4 \\
\hline None of the above & 3 & 8.6 \\
\hline Total & $\mathbf{3 6}$ & $\mathbf{1 0 0} \%$ \\
\hline
\end{tabular}

The table above shows the response rate of respondents on the proficiency of web technology by the staff. The above table indicates that $1(2.9 \%)$ are proficient with topic-specific websites, $5(14.3 \%)$ indicates that they are proficient with library websites, $9(25.7 \%)$ are proficient with e-mail, $5(14.3 \%)$ indicates that they are proficient with electronic books (digital) while 2(5.1\%) shows that some staff are proficient with on-line database. The highest respondents which is the e-mail with $9(25 \%)$ respondents indicates that the emergence of digital age has brought about the libraries automate their core operations like circulation, serial and cataloguing. Libraries have also created websites which facilitate access to their local resources outside the library. The table above shows that $29(5.7 \%)$ respondents responded to be familiar with on-line database. The reason is that patrons can now search on-line databases and access the library website remotely, independent of time and distance thereby transforming the use of library materials and the way library provides it services.

Types of computer training and workshop attended.

\begin{tabular}{|l|l|l|}
\hline $\begin{array}{l}\text { Training and } \\
\text { workshop }\end{array}$ & Frequency & Percentage \\
\hline Comp annreciation & 14 & 35.9 \\
\hline Comp program & 10 & 25.6 \\
\hline Website design & 4 & 10.3 \\
\hline Search skills & 5 & 12.8 \\
\hline Comp networking & 3 & 7.7 \\
\hline None of the & 2 & 5.1 \\
\hline Others & 1 & 2.6 \\
\hline Total & $\mathbf{3 9}$ & $\mathbf{1 0 0} \%$ \\
\hline
\end{tabular}


The table above shows the rate of response of respondents of the types of computer training and workshops attended by the staff. 14(35.9\%) responded that they have attended computer appreciation training, $10(25.6 \% \mathrm{o})$ indicated that they have attended basic computer programming, $5(12.8 \%)$ indicate they have attended internet search skills, 31(1.1\%) indicates basic computer networking and $1(2.6 \% \mathrm{o})$ indicate that they have attended other trainings. We can deduce that most of the staff have attended one or more training. Presently the library organizes computer training programme for its staff in the Iya Abubakar computer centre at $(50 \%)$ discount for the staff. This is to allow for the staff to have some basic computer skills to meet the needs of patrons in the digital environment like ours.

\section{Types of library automation training.}

\begin{tabular}{|l|l|l|}
\hline Trainings & Frequency & Percentage \\
\hline CISS/WISS & - & - \\
\hline ALICE & 19 & 52 \\
\hline TINL1B & - & - \\
\hline XLIB & 4 & 11.1 \\
\hline VTLS & 11 & 30.6 \\
\hline None & 2 & 5.6 \\
\hline Total & $\mathbf{3 6}$ & $\mathbf{1 0 0} \%$ \\
\hline
\end{tabular}

The table above shows the responses of the respondents on the types of library automation training attended by the library staff. The table above indicates that $19(52.8 \%)$ ) had training on Alice for windows, $4(11.1 \%)$ ) had training on XLIB, 11(30.6\%) had training on VTLS, 2(5.6\%) has never had training on any of the programs. The fact behind this is that the library is using Alice for windows and many staff were trained on how to use the software. The table also shows that the least automation training attended by the staff is the XLIB. The reason is because the libraries have not been using the software but were only trained on how it works. This indicates that library staff have not been using XLIB and have not been trained on it.

\section{Staff sponsorship}

\begin{tabular}{|l|l|l|}
\hline Sponsorship & Frequency & Percentage \\
\hline University management & 3 & 9.1 \\
\hline Library management & 10 & 30.3 \\
\hline Inernatn. funding & - & - \\
\hline MTN & 6 & 18.2 \\
\hline Self & 14 & 42.4 \\
\hline Others & - & - \\
\hline Total & $\mathbf{3 3}$ & $\mathbf{1 0 0 \%}$ \\
\hline
\end{tabular}

The Table above shows the responses of the respondent on the types of sponsorship the staff receives. 14(42.4\%) respondents responded that they sponsor themselves for seminars and training. This is because most of the staff managing the library are junior staff who have to get to some level before they can be chosen to go for training by the library management. The table also indicates that 10(30.3\%) respondents responded that the library management sponsor them to training and seminars. The reason is that Kashim Ibrahim Library is still undergoing automation process so there is need for more training of staff to become effective and efficient.

\section{Conclusion}

By carrying out this research, the researcher was able to have insight into the skills and knowledge needed to work in an electronic environment. Through the findings the researcher discovered factors responsible for lack of knowledge and skills for the academic librarians of the MTN-Net library and the Kashim Ibrahim Library of the Ahmadu Bello University Zaria. In view of this, the conclusion is that academic librarians do not have enough knowledge and skills needed to work in an electronic environment like ours. Another finding is that there is lack of technical support for the system section. Only one librarian is formally trained to initiate, develop, implement, and maintain computer applications in the entire university system. Coincidentally, those who train have only limited, or no access to the packages in which they had been trained because the staff knowledge on IT is still low. 


\section{Recommendations}

From the analysis and finding in this research, the researcher wishes to Recommend that:

1. Acquisition of technologies into the library should give preference to those that enhances access to digital content and capable of enhancing global visibility of local contents.

2. Information professionals must not only be aware, but they should be trained to get involved to efficiently and effectively discharge their duties.

3. More library automation training should be organized for staff to enable them cope with the digital advancement and on how to aggregate online information techniques to diversify search, evaluate internet service providers and the technicalities supporting uploading and holding local material on the internet.

4. Junior staff should also be released and sponsored to training irrespective to enable them to also meet the needs of patrons when on duty

[1]. Ajaji, O.G. (2003) National Infrastructure and support for a virtual library retrieved on 10/28/2006 from http://www.nitdsgov.ng/docs/paper/n itdavirtlab.ppt

[2]. Cleveland (1998). Virtual libraries: definition issues and challenges retrieve on 11/25/2006, from http;//www.ifk.org./vl/5/op/udtop 8.Htm.

[3]. Gbaje, S.E. (2007). Implementing a National virtual Library for higher Institutions in Nigeria.

[4]. Henson A. and Levin L.B (2003). Building virtual library

[5]. Lagoze C. et al (2005) what is a digital library anymore, anyway? Beyond search and access in the NSDL. National University Commission Executive Secretary's office. Retrieved on 02/04/2007.

[6]. Pettojohn, P. and Neville T. (2003). Collection development for virtual libraries

[7]. Thomas R. and Jose and L.R (2003). Library and information systems from automation to distributed information access solutions, greenwood publishing group.

[8]. Uhegbu, N.A. (2003). Constraints on the formulation and Journal of information science, 31 (2) 2004, pp 41-47a.

[9]. Pradeepa, W. (2003). The survival of the National institute of library and information sciences in a turbulent public university environment in maligning journal of library and information science, vol. 3 no 2 .

[10]. Uhegbu, N.A. (2003) Constraints on the formulation and Journal of information science. 31 (2) 2004, pp 41-47. 